\title{
Bacteriological Profile and Antibiogram of Uropathogens from a Tertiary Care Hospital: A Two Year Retrospective Analysis
}

\author{
Shivani Raina and Dipender Kaur Najotra*
}

Deptt. of Microbiology, Acharya Shri Chander College of Medical Sciences and Hospital Jammu, Jammu and Kashmir, India

*Corresponding author

\begin{tabular}{|l|}
\hline Ke y w o r d s \\
UTI, Uropathogen, \\
Bacteriology, \\
Antibiogram, \\
E. coli
\end{tabular}

A B S T R A C T

Urinary tract infections (UTIs) are one of the most common bacterial infections encountered in clinical practice. The knowledge of etiology and antibiogram of uropathogens helps in starting empirical treatment till the results of antibiotic susceptibility is awaited. Therefore this two year retrospective study was undertaken to determine the bacteriology and antimicrobial susceptibility pattern of UTIs in a tertiary care hospital. Urine samples from patients suspected of having UTI were processed according to standard microbiological techniques. Bacterial pathogens were isolated, identified and antimicrobial susceptibility testing was done by Kirby Bauer Disc Diffusion from 286 culture positive samples. Escherichia coli with 186(65\%) isolates was predominant followed by Klebsiella pneumoniae 30(10.5\%), Pseudomonas aeruginosa 20(7\%), Enterococcus spp. 13(4.6\%), Proteus spp. 10(3.5\%), Acinetobacter spp. 8(2.8\%), Staphylococcus aureus 7(2.4\%) and Coagulase negative Staphylococci (CoNS) 6(2.1\%). Antibiogram of these bacteria suggests that empirical therapy to cover gram negative bacteria can be started with imipenem or piperacillin /tazobactum or nitrofurantoin. In selected cases vancomycin or linezolid can be added to give gram positive coverage. But in view of the increasing drug resistance antimicrobial susceptibility should be done and definitive therapy started immediately.

\section{Introduction}

Urinary tract infections (UTI) include various conditions ranging from asymptomatic bacteriuria to severe renal infections resulting into sepsis and can affect any part of the urinary tract from the bladder to the kidney (Kumar et al., 2016, and Flores-Mireles et al., 2015). It is estimated that annually, worldwide 7 million and 1million patients with UTI attend the outpatient and emergency department respectively. Whereas 100,000 hospitalizations occur annually due to UTI (Wilson et al., 2004). Most of the times these UTIs are treated empirically without any antibiotic susceptibility testing which leads to increased drug resistance in bacteria against commonly used antibiotics (Chiu, 2013). Also in the last two decades it has been seen that the trend of bacterial isolates obtained and their antibiotic sensitivity pattern keeps on 
changing (Ram et al., 2000).

Therefore updated information regarding profile of uropathogens and there susceptibility to various antibiotics should be readily available to the clinicians for the development of local data to start appropriate empirical therapy (Majumder et al., 2018; Oli et al., 2017; Vakilwala et al., 2012 and Ko et al., 2008). So with this background, the present study aimed at investigating the bacterial agents responsible for UTIs in a tertiary care hospital setting and study their antibiotic susceptibility pattern.

\section{Materials and Methods}

This retrospective study was conducted in a tertiary care hospital over a period of two years, from January 2016 to December 2017 after approval from institutional ethical committee. Clean catch midstream urine or catheterized urine samples were collected in a wide mouthed sterile screw capped containers from suspected patients of UTI. Urine samples were taken to bacteriology lab and processed immediately within half an hour of collection. Samples were inoculated semiquantitatively with calibrated loop on Blood agar and McConkey agar and incubated aerobically overnight at $37^{\circ} \mathrm{C}$. Pure growth of a single microorganism with a colony count of $>10^{5}$ colony forming units $(\mathrm{cfu}) / \mathrm{mL}$ of urine was considered as significant bacteriuria (Stamm et al., 1983). Further, the significant isolates were identified by conventional biochemical methods according to standard microbiological techniques (Collee et al., 2006). Antibiotic Susceptibility Testing was done on Mueller- Hinton agar by Kirby Bauer's disc diffusion method, according to the CLSI guidelines, 2016. The following antimicrobial discs $(\mu \mathrm{g})$ were used:

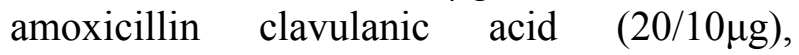
piperacillin tazobactam $(100 / 10 \mu \mathrm{g})$, amikacin $(30 \mu \mathrm{g})$, co-trimoxazole $(25 \mu \mathrm{g})$, gentamicin
$(10 \mu \mathrm{g})$, tobramycin $(10 \mu \mathrm{g})$, nitrofurantoin $(300 \mu \mathrm{g})$, cefepime $(30 \mu \mathrm{g})$, cefotaxime $(30 \mu \mathrm{g})$, cefuroxime $(30 \mu \mathrm{g}), \quad$ ceftazidime $(30 \mu \mathrm{g})$, imipenem $(10 \mu \mathrm{g})$, Polymyxin $\mathrm{B}(300 \mathrm{U})$, Penicillin(10U), ciprofloxacin $(5 \mu \mathrm{g})$, norfloxacin $(10 \mu \mathrm{g})$, vancomycin $(30 \mu \mathrm{g})$, Linezolid $(15 \mu \mathrm{g})$. Escherichia coli ATCC 25922 Staphylococcus aureus ATCC 25923 were used as control strains.

\section{Data management and statistical analysis}

Statistical Package for Social Science (SPSS) Software, version 16 was used for data analysis. Chi-square test was performed to obtain the correlations between variables.

\section{Results and Discussion}

During the study period, 984 urine samples were analyzed out of which $286(29.1 \%)$ were culture positive. Of these culture positive samples, $173(60.5 \%)$ were from female patients and 113 (39.5\%) from male patients. Of the 286 isolates, 254 (88.8\%) were Gram negative bacilli, $26(11.2 \%)$ were Gram positive cocci and $6(2.1 \%)$ were Candida spp. Amongst the Gram negative isolates, Escherichia coli with 186(65\%) was predominant followed by Klebsiella pneumoniae 30 (10.5\%), Pseudomonas aeruginosa 20 (7\%), Proteus spp. 10(3.5\%) and Acinetobacter spp. $8(2.8 \%),(\mathrm{p}=0.0001$ significant). Amongst Gram positive isolates, Enterococcus spp. 13(4.6\%) was commonest followed by Staphylococcus aureus 7(2.4\%) and Coagulase negative Staphylococcus 6(2.1\%) (Fig. 1).

As far as antibiogram of gram negative bacteria is concerned, Imipenem was the most effective drug with sensitivity ranging from 80-100\%. Piperacillin/tazobactum showed good sensitivity against Proteus spp (80\%) and E.coli (77.4\%). Amikacin had good sensitivity profile against $E$. coli $(79.6 \%)$ and 
Proteus spp. (70\%). Nitrofurantoin was also an effective antibiotic against $E$. coli with $81.2 \%$ sensitivity. Polymyxin B was quite effective against Pseudomonas spp. and Acinetobacter spp with $95 \%$ and $87.5 \%$ sensitivity respectively. Gram negative bacterial isolates were highly resistant to cotrimoxazole, fluoroquinolones and cephalosporins like cefepime, cefotaxime, ceftazidime, cefuroxime (Table 1).

Gram positive isolates showed $100 \%$ sensitivity to Linezolid and Vancomycin. Nitrofurantoin also turned out to be effective with Staphylococcus aureus showing 100\% sensitivity and CoNS $83.3 \%$. Fifty or less than fifty percent gram positive isolates were resistant to Norfloxacin. Majority of the gram positive bacteria were resistant to Penicillin and Co-trimaxazole (Table 2).

This study gives an insight into UTI, one of the most common infections leading to an antibiotic prescription from a tertiary care hospital. The culture positivity rate was $29.1 \%$ from 984 urine samples received from the patients attending the hospital with the symptoms suggestive of UTI. This prevalence rate was similar to various national and other studies from the developing world (Majumder et al., 2018; Khadka et al., 2012; Joshi et al., 2016; Thattil et al., 2018 and Mandal et al., 2012). Greater prevalence of UTI was seen in females accounting for $60.5 \%$ of the positive samples, similar to other studies worldwide (Khadka et al., 2012; Joshi et al., 2016; Razak et al., 2012; Singh et al., 2017; John et al., 2015 and Mohammed et al., 2016). The predominant uropathogen in our study was $E$. coli followed by $K$. pneumoniae which is in agreement with many other studies from India and abroad (Majumder et al., 2018; Vakilwala et al., 2012; Khadka et al., 2012; Thattil et al., 2018; Razak et al., 2012; John et al., 2015 and Mohammed et al., 2016).

In the present study imipenem was found to be effective against more than $80 \%$ gram negative isolates as reported by numerous other studies (Majumder et al., 2018; Thattil et al., 2018; Singh et al., 2017; Mohammed et al., 2016; Vecchi et al., 2013 and Rangari et al., 2015). Piperacillin/ tazobactum showed a sensitivity of around $80 \%$ for E.coli and Proteus spp. isolates and around 65\% for Pseudomonas which is in concordance with many previous studies (Thattil et al., 2018; Vecchi et al., 2013; Rangari et al., 2015 and Singla et al., 2015). This drug was least effective against Acinetobacter as reported by Berry et al., (2013). Amikacin also proved to be a good alternative against E. coli, Proteus spp. and Pseudomonas spp. but had limited activity against Acinetobacter isolates which is in harmony with other studies (Vakilwala et al., 2012; Joshi et al., 2016; Razak et al., 2012 and Vecchi et al., 2013). Nitrofurantoin turned out is very active against $E$. coli which is the predominant urinary isolate similar to previous reports (Majumder et al., 2018; Rangari et al., 2015 and Singla et al., 2015 and Vecchi et al., 2013). High percentage of resistance against Nitrofurantoin was seen amongst isolates of other gram negative spp. as reported by Joshi et al., (2016) and Thattil et al., (2018). Gentamycin demonstrated a sensitivity rate of 50-55\% amongst most of the species similar to few other studies (Joshi et al., 2016; Mandal et al., 2012 and Rangari et al., 2015). Majority of the gram negative isolates were resistant to commonly used cephalosporins and co-trimoxazole as also reported by other researchers (Vakilwala et al., 2012; Razak et al., 2012; Mohammed et al., 2016; Rangari et al., 2015 and Singla et al., 2015 and Berry et al., 2013). Fluoroquinolones were also ineffective against majority isolates similar to previous reports (Razak et al., 2012; Rangari et al., 2015 and Berry et al., 2013). Amoxycillin/ clavulanate proved to be least effective in treating gram negative UTI which is in concordance with some other studies done by Majumder et al., 
(2018) and Thattil et al., (2018). As far as gram positive cocci are concerned vancomycin and linezolid were the most effective with $100 \%$ sensitivity as reported from many other places (Thattil et al., 2018; Singla et al., 2015; Vecchi et al., 2013 and Rangari et al., 2015). The next effective drug against UTI due to gram positive cocci was nitrofurantoin which is similar to previous reports by Singla et al., (2015) and Vecchi et al., (2013). Very high resistance was seen to ciprofloxacin amongst enterococcal isolates which was in line with other studies by Thattil et al., (2018) and Rangari et al., (2015).

Table.1 Antibiotic sensitivity profile of Gram negative isolates ( $\mathrm{N}=254)$

\begin{tabular}{|c|c|c|c|c|c|}
\hline $\begin{array}{l}\text { Antimicrobial } \\
\text { agent }\end{array}$ & $\begin{array}{l}\text { E.coli } \\
(\mathrm{N}=186)\end{array}$ & $\begin{array}{l}\text { K.pneumoniae } \\
(\mathbf{N}=30)\end{array}$ & $\begin{array}{l}\text { Pseudomonas } \\
(\mathrm{N}=\mathbf{2 0})\end{array}$ & $\begin{array}{l}\text { Proteus } \\
(\mathrm{N}=10)\end{array}$ & $\begin{array}{l}\text { Acinetobacter } \\
(\mathrm{N}=8)\end{array}$ \\
\hline $\begin{array}{l}\text { Amoxycillin/ } \\
\text { clavulanate }\end{array}$ & $25(13.4 \%)$ & $0(0 \%)$ & $1(5 \%)$ & $3(30 \%)$ & $1(12.5 \%)$ \\
\hline $\begin{array}{l}\text { Piperacillin/ } \\
\text { tazobactum }\end{array}$ & $144(77.4 \%)$ & $12(40 \%)$ & $13(65 \%)$ & $8(80 \%)$ & $2(25 \%)$ \\
\hline Amikacin & $148(79.6 \%)$ & $10(33.3 \%)$ & $10(50 \%)$ & $7(70 \%)$ & $2(25 \%)$ \\
\hline $\begin{array}{l}\text { Co- } \\
\text { trimoxazole }\end{array}$ & $48(25.8 \%)$ & $9(30 \%)$ & $6(30 \%)$ & $0(0 \%)$ & $4(50 \%)$ \\
\hline Gentamycin & $105(56.5 \%)$ & $8(26.7 \%)$ & $11(55 \%)$ & $5(50 \%)$ & $4(50 \%)$ \\
\hline Tobramycin & - & - & $10(50 \%)$ & $5(50 \%)$ & $6(75 \%)$ \\
\hline Nitrofurantoin & $151(81.2 \%)$ & $2(6.7 \%)$ & $3(15 \%)$ & $5(50 \%)$ & $2(25 \%)$ \\
\hline Ciprofloxacin & $56(30.1 \%)$ & $10(33.3 \%)$ & $6(30 \%)$ & $3(30 \%)$ & $1(12.5 \%)$ \\
\hline Norfloxacin & $30(16.1 \%)$ & $5(16.7 \%)$ & $5(25 \%)$ & $2(20 \%)$ & $2(25 \%)$ \\
\hline Cefepime & $49(26.3 \%)$ & $5(16.7 \%)$ & $5(25 \%)$ & $2(20 \%)$ & $1(12.5 \%)$ \\
\hline Cefotaxime & $39(21 \%)$ & $2(6.7 \%)$ & $5(25 \%)$ & $4(40 \%)$ & $3(37.5 \%)$ \\
\hline Cefuroxime & $21(11.3 \%)$ & $2(6.7 \%)$ & $1(5 \%)$ & $2(20 \%)$ & $1(12.5 \%)$ \\
\hline Ceftazidime & $45(24.2 \%)$ & $3(10 \%)$ & $6(30 \%)$ & $2(20 \%)$ & $2(25 \%)$ \\
\hline Imipenem & $185(99.5 \%)$ & $28(93.3 \%)$ & $16(80 \%)$ & $10(100 \%)$ & $8(100 \%)$ \\
\hline Polymixin B & 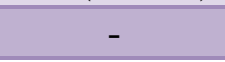 & - & $19(95 \%)$ & - & $7(87.5 \%)$ \\
\hline
\end{tabular}

Table.2 Antibiotic sensitivity profile of gram positive isolates ( $\mathrm{N}=26)$

\begin{tabular}{|l|l|l|l|}
\hline Antimicrobial agent & \multicolumn{1}{|c|}{$\begin{array}{c}\text { S. aureus } \\
(\mathbf{N = 7})\end{array}$} & $\begin{array}{c}\text { CONS } \\
(\mathbf{N = 6})\end{array}$ & $\begin{array}{c}\text { Enterococcus spp. } \\
\text { (N=13) }\end{array}$ \\
\hline Penicillin & $1(14.3)$ & $2(33.3)$ & $3(23.1)$ \\
\hline Co-trimaxazole & $2(28.6)$ & $1(16.7)$ & $5(38.5)$ \\
\hline Gentamicin & $5(71.4)$ & $4(66.7)$ & $4(30.8)$ \\
\hline Ciprofloxacin & $3(42.9)$ & $4(66.7)$ & $0(0)$ \\
\hline Norfloxacin & $2(28.6)$ & $3(50)$ & $4(30.8)$ \\
\hline Nitrofurantoin & $7(100)$ & $5(83.3)$ & $9(69.2)$ \\
\hline Vancomycin & $7(100)$ & $6(100)$ & $13(100)$ \\
\hline Linezolid & $7(100)$ & $6(100)$ & $13(100)$ \\
\hline
\end{tabular}

Fig.1 Distribution of culture isolates 


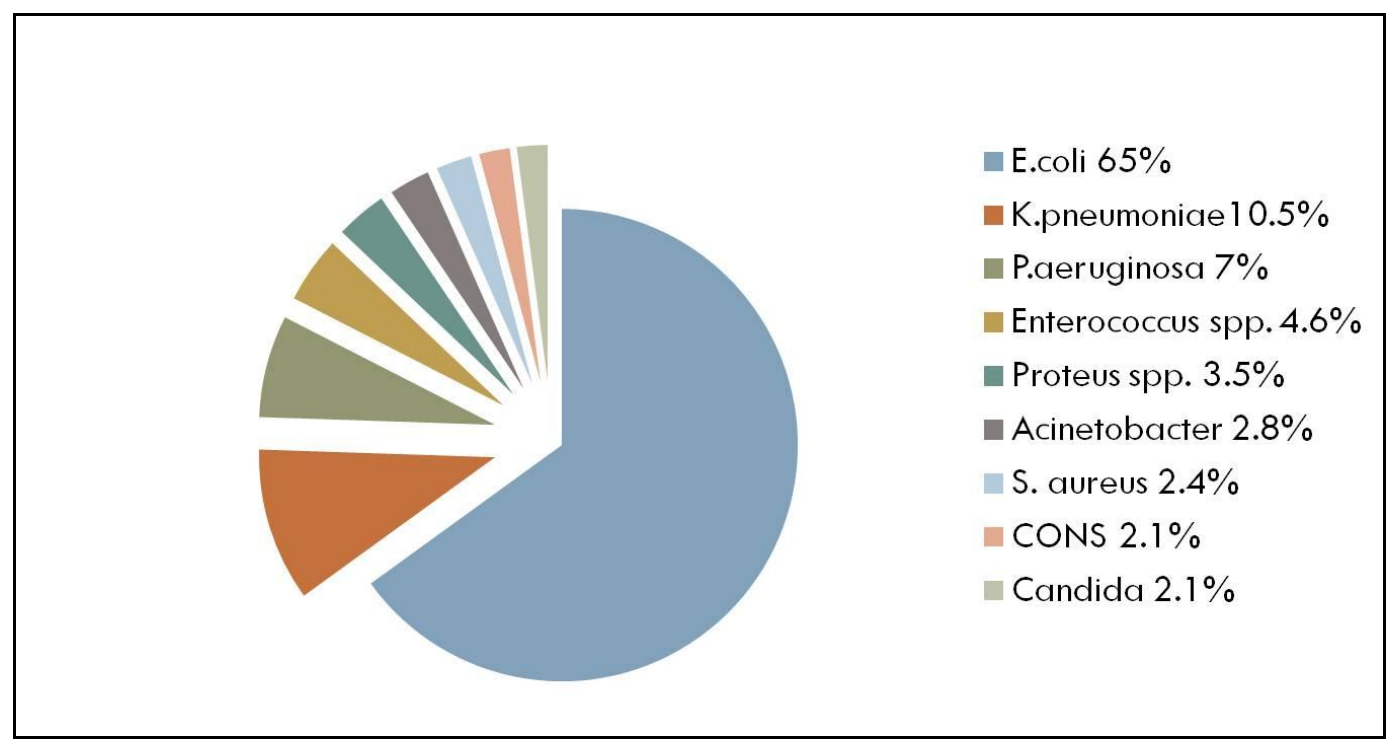

Sensitivity of Stapyhlococcus aureus to ciprofloxacin was $42.9 \%$ which is comparable to other studies from UP and Nepal (Khadka et al., 2012 and Rangari et al., 2015). Gentamycin turned out to be effective against $70 \%$ of the staphylococcal isolates as reported by other workers (Khadka et al., 2012; Vecchi et al., 2013 and Rangari et al., 2015). On the contrary Enterococcus isolates showed high resistance to gentamicin which has also been reported in few studies (Joshi et al., 2016 and Thattil et al., 2018). Co-trimoxazole and penicillin were also ineffective against majority of the isolates as in other studies (Khadka et al., 2012; Vecchi et al., 2013 and Thattil et al., 2018).

Therefore this study concludes that $E$. coli is the most likely organism encountered in UTI and most of the strains isolated from a tertiary care hospital are multi drug resistant. Empirical therapy to cover gram negative bacteria can be started with imipenem or piperacillin /tazobactum or nitrofurantoin. In selected cases vancomycin or linezolid can be added to give gram positive coverage. But in view of the increasing drug resistance, antimicrobial susceptibility should be done and definitive therapy started immediately.

\section{References}

Berry, B., Kedia, C., Grewal, L.K., Goyal, M. 2013. Acinetobacter: an opportunistic uropathogen. Ind. J. Sci. Res. and Tech.; 1(1):35-7.

Chiu, C. 2013. Definitions, classifications, and antibiotics. In: Ran'e A, Dasgupta $\mathrm{R}$, editors. Urinary tract infection: clinical perspectives on urinary tract infection. London: Springer-Verlag. p. $1-10$.

CLSI. 2016. Performance standards for antimicrobial disk tests; Approved Standards. 25th Edition. Clinical and Laboratory Standards Institute (CLSI) Document M2-A9. Wayne.; 26.(1).

Collee, J.G., Fraser, A.G., Marmion, B.P., Simmin, A. 2006. Mackie and McCartney practical medical microbiology, 14th Edition, Pearson professional 1996, New York: 8485,152 .

Flores-Mireles, A.L., Walker, J.N., Caparon, M., Hultgren, S.J. 2015. Urinary tract infections: Epidemiology, mechanisms of infection and treatment options. Nat Rev Microbiol. 13(5): 269-84. [http://dx.doi.org/10.1038/nrmicro343 2] [PMID: 25853778]. 
John, M.S., Meenakshi, K., Lakshmi, P.M., Reddy, P.S. 2015. Prevalence and Distribution of Bacterial Pathogens Causing Urinary Tract Infections in Humans: A Study from Tertiary Care Hospital in AP, India. Int.J.Curr.Microbiol.App.Sci. $\quad 4(2)$ : 251-7.

Joshi, Y., Shrestha, S., Kabir, R., Thapa, A., Upreti, P., and Shrestha, S. 2016. Urinary tract infections and antibiotic susceptibility among the patients attending B \& D hospital of Lalitpur, Nepal. Asian Journal of Medical Sciences, 7(5), 47-51. doi: http://dx.doi.org/10.3126/ajms.v7i5.14 908.

Khadka, K.S., Khadka, J., Lekhak, B., Shrestha, P. and Tiwari, B.R. 2012. Incidence of urinary tract infection among the patients visiting western regional hospital, Pokhara, Nepal. Journal of Health and Allied Sciences. 2(1):35-37.

Ko, M.C., Liu, C.K., Woung, L.C., Lee, W.K., Jeng, H.S., Lu, S.H., et al., 2008. Species and antimicrobial resistance of uropathogens isolated from patients with urinary catheter. Tohoku Journal of Experimental Medicine. 214(4): 311-19.

Kumar, G.V., Aaron, G., Viswanathakumar, H.M. 2016. Study of clinical profile and risk factors associated with febrile urinary tract infection in preschool children. Int J Contemp Pediatr. 3(1): 243-246.

Majumder, M.I., Ahmed, T., Sakib, N., Khan, A.R., Saha, C.K. 2018. A Follow up Study of Bacteriology and Antibiotic Sensitivity Pattern of Urinary Tract Infection in a Tertiary Care Hospital in Bangladesh. J Bacteriol Parasitol 9: 334. doi:10.4172/2155-9597.1000334

Mandal, J., Acharya, N.S., Buddhapriya, D.,Parija, S,C. 2012. Antibiotic resistance pattern among common bacterial uropathogens with a special reference to ciprofloxacin resistant Escherichia coli. Indian $\mathrm{J}$ Med Res. 136(5):842-9.

Mohammed, M.A., Alnour, T. M. S., Shakurfo, O.M., Aburass, M.M. 2016. Prevalence and antimicrobial resistance pattern of bacterial strains isolated from patients with urinary tract infection in Messalata Central Hospital, Libya. Asian Pacific Journal of Tropical Medicine; 9(8): 771-6.

Oli, A.N., Akabueze, V.B., Ezeudu, C.E., et al., 2017. Bacteriology and Antibiogram of Urinary Tract Infection Among Female Patients in a Tertiary Health Facility in South Eastern Nigeria. Open Microbiol J. 11: 292-300. Published 2017 Oct 31. doi:10.2174/1874285801711010292

Ram, S., Gupta, R., Gaheer, M. 2000. Emerging antibiotic resistance among uropathogens. Ind J Med Sci. 54: 388394.

Rangari, A.A., Sharma, S., Tyagi, N. 2015. Antibiotic Susceptibility Pattern of Bacterial Uropathogens Isolated from Patients at a Tertiary Care Hospital in Western Uttar Pradesh of India. Int.J.Curr.Microbiol.App.Sci. $\quad 4(10)$ : 646-657.

Razak, S.K., Gurushantappa, V. 2012. Bacteriology of urinary tract infection and antibiotic susceptibility pattern in a tertiary care hospital in South India. Int J Med Sci Public Health. 1:109112.

Singh, V.P., Mehta, A. 2017. Bacteriological profile of urinary tract infections at a tertiary care hospital in Western Uttar Pradesh, India. Int J Res Med Sci. 5:2126-9.

Singla, P., Sangwan J., Garg, S. 2015. Prevalence and antibiogram of multidrug resistant uropathogenic 
isolates of Proteus mirabilis in a teaching tertiary care hospital. Int.J.Curr.Microbiol.App.Sci. $\quad 4(12)$ : 675-682.

Stamm, W.E. 1983. Measurement of pyuria and its relation with bacteriuria. Am J Med. 75:53-8.

Thattil, S., Santhosh, S. 2018. Prevalence of UTI in different age groups in a tertiary care hospital and their antibiogram. International Journal of Contemporary Medical Research. 5(1): 3-6.

Vakilwala, M, Trivedi, R. 2012. Prevalence of antimicrobial resistance in uropathogens and determining empirical therapy for urinary tract infections. International Journal of Pharma and Bio Sciences. 3(2):436440.

Vecchi, E.D., Sitia S., Romano C.L. 2013. Aetiology and antibiotic resistance patterns of urinary tract infections in the elderly: a 6-month study. Journal of Medical Microbiology. 62, 859863.

Wilson, M.L., Gaido, L. 2004. Laboratory diagnosis of urinary tract infections in adult patients. Clin Infect Dis. 38:1150-1158.

\section{How to cite this article:}

Shivani Raina and Dipender Kaur Najotra. 2019. Bacteriological Profile and Antibiogram of Uropathogens from a Tertiary Care Hospital: A Two Year Retrospective Analysis. Int.J.Curr.Microbiol.App.Sci. 8(01): 1206-1212. doi: https://doi.org/10.20546/ijcmas.2019.801.127 